Supporting Information

\title{
Environmental photochemistry of tylosin: efficient, reversible photoisomerization to a less-active isomer, followed by photolysis
}

Jeffrey J. Werner ${ }^{\dagger}$, Mahati Chintapalli ${ }^{\ddagger}$ Rachel A. Ludeen ${ }^{\S}$, Kristine H. Wammer ${ }^{\S}$, William A. Arnold ${ }^{\dagger *}$, and Kristopher McNeilli,\#,**

${ }^{\dagger}$ Water Resources Science Program, University of Minnesota, 1985 Buford Avenue, St. Paul, MN 55108, USA;

${ }^{7}$ Department of Civil Engineering, University of Minnesota, 500 Pillsbury Drive SE, Minneapolis, MN 55455-0116,

USA; ${ }^{\S}$ Department of Chemistry, University of Saint Thomas, 2115 Summit Avenue, St. Paul, MN 55105, USA ;

${ }^{\#}$ Department of Chemistry, University of Minnesota, 207 Pleasant St. SE, Minneapolis, MN 55455, USA

\section{Contents}

Description of photochemical experiments and the calculations performed...............................S2

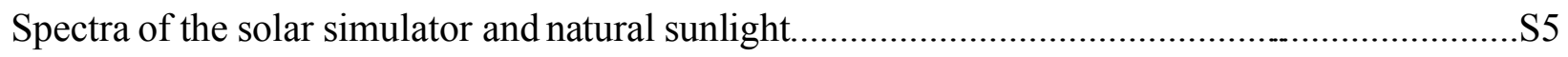

HPLC chromatogram of tylosin and photoisomer................................................................ 6

Kinetic data for concentration-dependent and $\mathrm{pH}$-dependent photolysis..................................S7

Kinetic data for photolysis with varied SRFA concentration..............................................S8

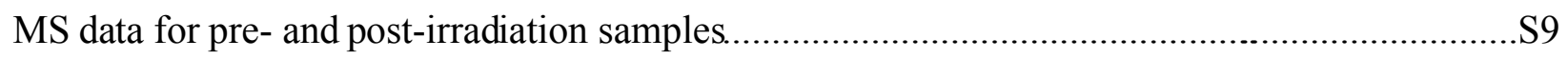

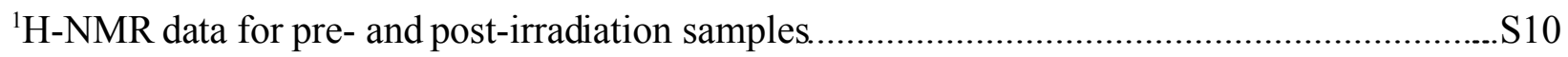

Concentration-corrected pla of the data in Figure 1 and a fit to Equation 3.............................S11

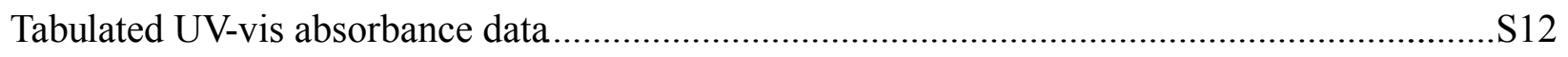

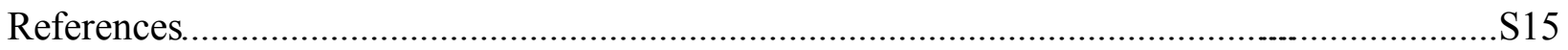




\section{Photolysis Experiments}

To predict the environmental photochemical kinetics of a pollutant in a given aqueous system, a number of variables need to be measured or estimated. These include the wavelength-dependent sunlight intensity, $\mathrm{I}(\lambda)$, the solar geometry with respect to the water surface, cloud cover, average water depth, and the light attenuation and scattering characteristics of the water column. A helpful publication is available by Leifer (1988), which includes a detailed procedure for modeling these processes, partially based on the equations developed in Zepp and Cline(1977). Prediction of environmental photolysis kinetics in surface water can be aided by the software package GCSOLAR, maintained and distributed by the US EPA.

The modeling of environmental photolysis requires estimating the average light intensity spectrum, $I_{\text {ave }}(\lambda)$, to which the compound of concern is exposed. The other two pieces of information needed to quanify kinetics are (1) the relative rate at which the compound absorbs incident radiation as a function of wavelength, and (2) the probability that a photon absorption event will lead to loss of the compound. The average rate of light absorption, $k_{\text {absorb }}$, can be calculated using the product of the decadic molar absorptivity, $\varepsilon(\lambda)$, and $I_{\text {ave }}(\lambda)$ :

$$
k_{\text {absorb }}=\ln (10) \int \varepsilon(\lambda) I_{\text {ave }}(\lambda) d \lambda
$$

With the appropriate units for $I_{\text {ave }}(\lambda)$ and $\varepsilon(\lambda)$ (i.e., Ein $\mathrm{cm}^{-2} \mathrm{~s}^{-1}$ and $\mathrm{mL} \mathrm{mol}^{-1} \mathrm{~cm}^{-1}$ respectively), $k_{\text {absorb }}$ will have units of photons absorbed per molecule per unit time (i.e., Ein $\mathrm{mol}^{-1} \mathrm{~s}^{-1}$ ). With constant light intensity, the photon absorption process is pseudo-first-order in compound concentration.

From the standpoint of quantifying the loss of the compound of interest, there are two possible outcomes of interest which can result from photon absorption: (1) chemical transformation 
resulting in loss of the parent compound or(2) eventual relaxation and return to the ground state. An empirical parameter, quantum yield $\left(\Phi_{\text {direct }}\right)$, is used to represent the probability that absorption of a photon will lead to the first of these two possibilities, loss of the parent compound. The pseudo-first-order rate constant for direct photolysis, $k_{\text {direct, }}$ can then be calculated as the product of Equation S1 and $\Phi_{\text {direct, }}$ expanded in Equation S2.

$$
k_{\text {direct }}=\Phi_{\text {direct }} k_{\text {absorb }}=\ln (10) \Phi_{\text {direct }} \int \varepsilon(\lambda) I_{\text {ave }}(\lambda) d \lambda
$$

The value of $\Phi_{\text {direct }}$ in the above equation is assumed to be wavelength-independent, an approximation which simplifies the calculation by allowing it to be incorporated as a single value outside of the integral. In a practical sense, $\Phi_{\text {direct }}$ is the polychromatic quantum yield for photolysis under natural sunlight. There are a few reasons to make this approximation. Although the relative solar spectrumcan vary from one system to another, it is similar enough under most circumstances for the variation to be insignificant in comparison to the error in $\Phi_{\text {direct. }}$ This means that if $\Phi_{\text {direct }}$ Was measured using the solar spectrum, it should apply to other systems irradiated with natural sunlight. Additional rationalization may be found in Kasha's Rule(Kasha, 1950) that after an excitation of $S \rightarrow S_{n}$, the most probable subsequent step is vibrational relaxation of $S_{n} \rightarrow S_{1}$. All subsequent competitive kinetic processes including $S_{1} \rightarrow S$ (via fluorescence or thermal relaxation) and $S_{1} \rightarrow T$ (inter-system crossing to the triplet state $T$ ) occur from the same intermediate, $S_{1}$, which results from every photon-absorption event. Assuming that all direct photochemical action goes through $S_{1}, \Phi_{\text {direct }}$ is the fraction of all possible outcomes starting from $S_{1}$ that do not ultimately lead back to $S$ of the parent compound.

There are still many cases in which $\Phi_{\text {direct }}$ will be wavelength-dependent, including the photochemistry of compounds that are an exception to Kasha's Rule. Other notable cases where 
the observed $\Phi_{\text {direct }}$ can depend strongly on wavelength is when multiple species of the compound are in rapid equilibrium with each other. Each species has its own absorption spectrum and quantum yield. If the incident light favors excitation of species A over species B, then the observed average $\Phi_{\text {direct }}$ will disproportionately reflect the photochemistry of A. If the light spectrum then changes to favor excitation of $B$, the observed $\Phi_{\text {direct }}$ will change accordingly. This has been reported as a significant effect of acid-base equilibria for some sulfa-drug antibiotics (Boreen et al., 2004) and the metal-binding equilibria of tetracycline (Werner et al., 2006). In these cases, knowledge of the fundamental $\Phi_{\text {direct }}$ values and absorbance spectra for each individual species allows one to account for this wavelength dependence.

To measure $\Phi_{\text {direct }}$ in the current study, quartz test tubes containing sample solutions were placed in parallel, facing the light source within a solar simulator. Tubes, as opposed to flat surfaces, offer the benefit of uniform, reproducible optics. The lens effect of the tube, approximately $\times 2$, was accounted for using an actinometer solution (Dulin and Mill, 1982). The use of an actinometer accounts for many of the experimental variables which affect light budget of the system, including incident radiation intensity, reflection, refraction, and the geometry of tube placement. When using a chemical actinometerin parallel to sample tubes, the physical variables affecting light intensity within the sample tube cancel out. We calculated the quantumyield using the following equation adapted from Leifer (1988)

$$
\Phi_{\text {direct }}=\frac{k_{\text {direct }} k_{\text {abs, act }}^{0}}{k_{\text {direct, act }} k_{\text {absorb }}^{0}} \Phi_{\text {act }}
$$

where $\Phi_{\text {act }}$ is the known polychromatic quantum yield of the actinometer, $k_{\text {abs,act }}^{0}$ and $k_{\text {absorb }}^{0}$ are the normalized rates of light absorption of the actinometer and the compound of interest, and $k_{\text {direct,act }}$ is the observed pseudo-first-order rate constant for actinometer loss. Light screening was corrected 
for using the light screening factor, $S$, which relates the direct photolysis rate constant at the surface, $k_{\text {direct, }}^{0}$ to the observed average rate constant $k_{\text {direct. }}$

$$
k_{\text {direct }}=S k_{\text {direct }}^{0}
$$

$S$ is calculated from the average path length $\left(z_{\text {ave }}\right)$ and the light attenuation coefficient $\alpha\left(\lambda_{\mathrm{m}}\right)$ of the solution at $\lambda_{\mathrm{m}}$, the wavelength at which the compound has its maximum specific rate of light absorption (Schwarzenbach et al., 2003).

$$
S=\frac{1-10^{-\alpha\left(\lambda_{m}\right) z_{\text {ave }}}}{\ln (10) \alpha\left(\lambda_{m}\right) z_{\text {ave }}}
$$

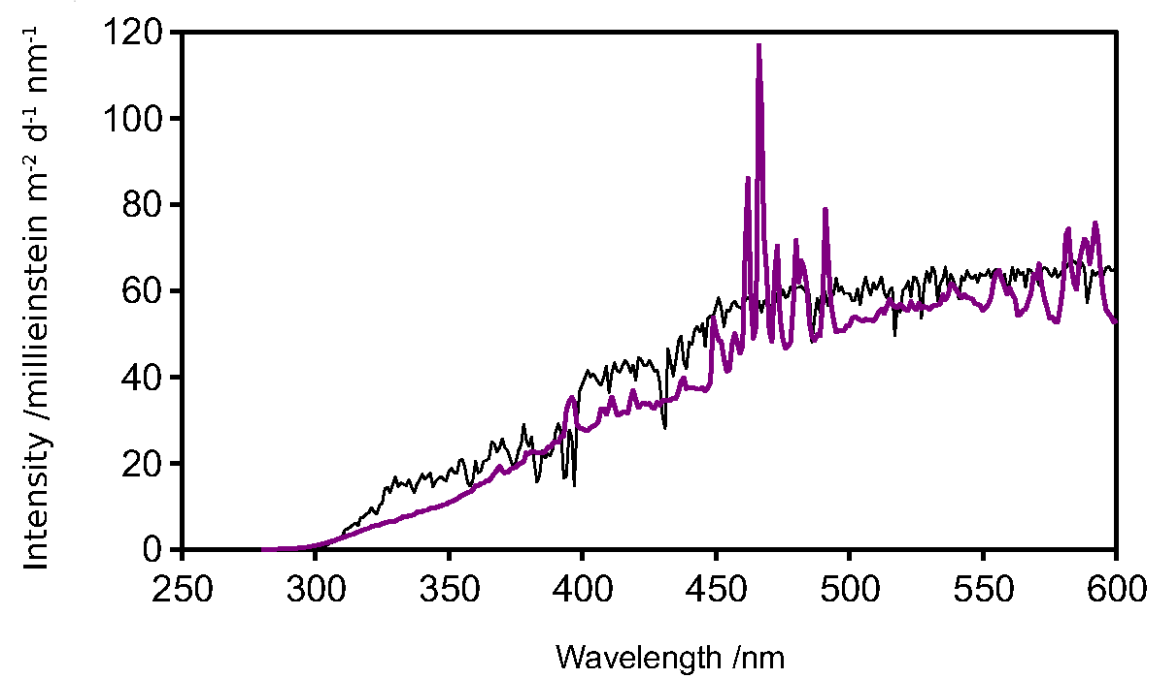

Figure S1. Emission spectrum of the solar simulator in the configuration used in this study (bold magenta line; obtained from the manufacturer, Atlas) along with the solar spectrum at noon, July, Minneapolis, MN (black line) modeled using the SMARTS software package (Gueymard, 1995; Gueymard, 2001). 

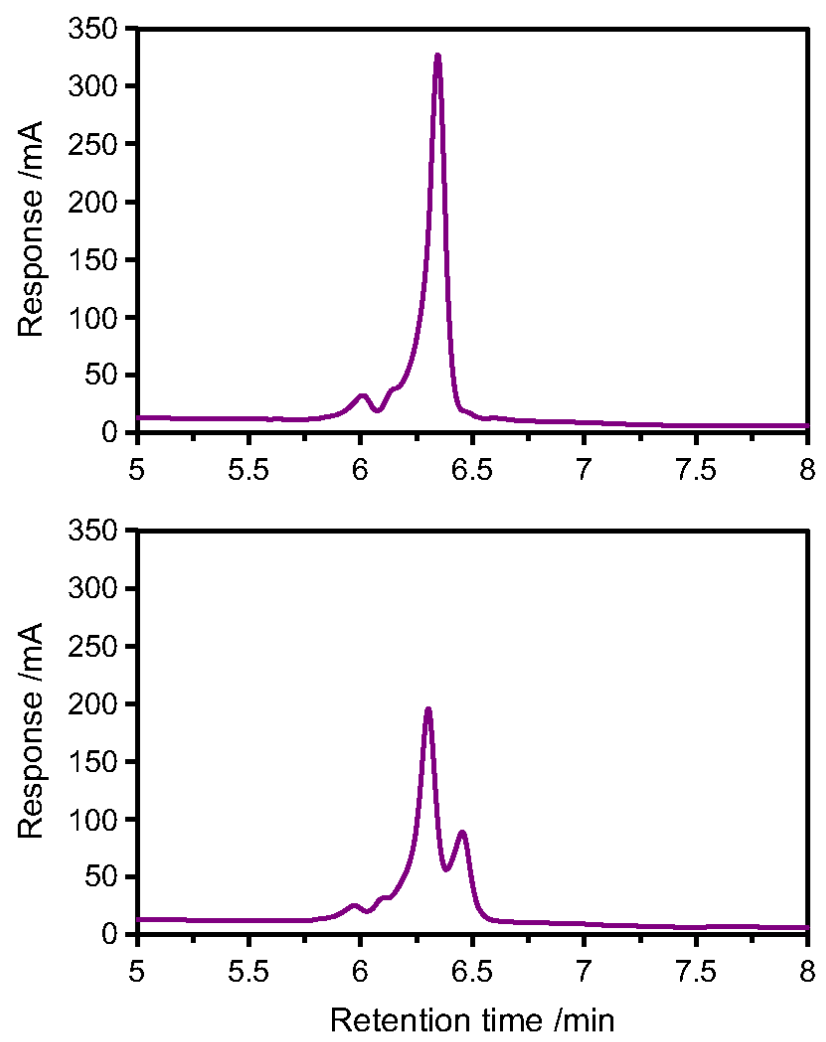

Figure S2. HPLC/UV-vis chromatogram of tylosin (top and bottom panel; RT=6.30 $\mathrm{min}$ ) and photoisomer (bottom panel; RT=6.45 $\mathrm{min}$ ) taken from an aqueous solution of tylosin which was irradiated 1 minute for the bottom panel. HPLC method is available in the main text. 


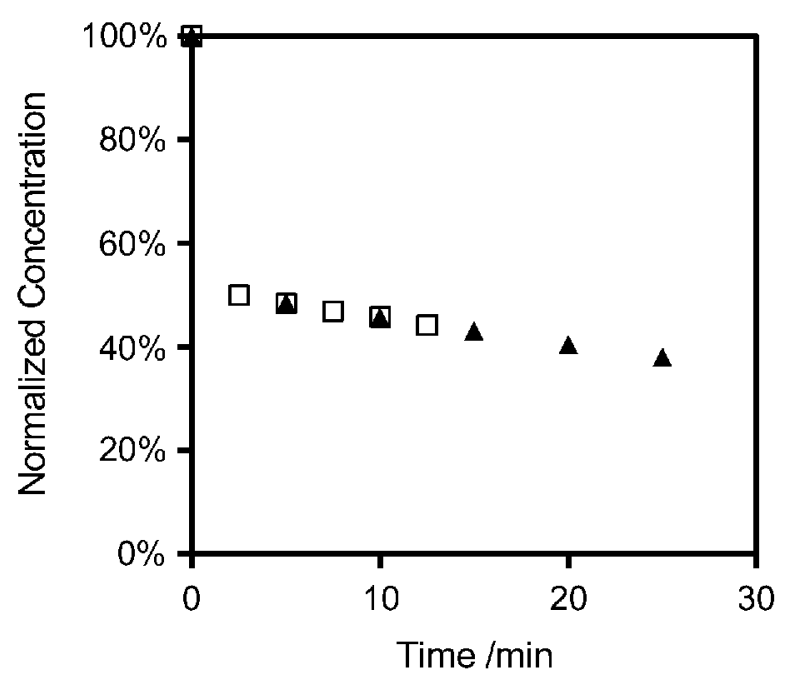

Figure S3. The photolysis of $10 \mu \mathrm{M}$ tylosin (open squares) and $100 \mu \mathrm{M}$ tylosin (closed triangles) in the solar simulator, $250 \mathrm{~W} \mathrm{~m}^{-2}$.

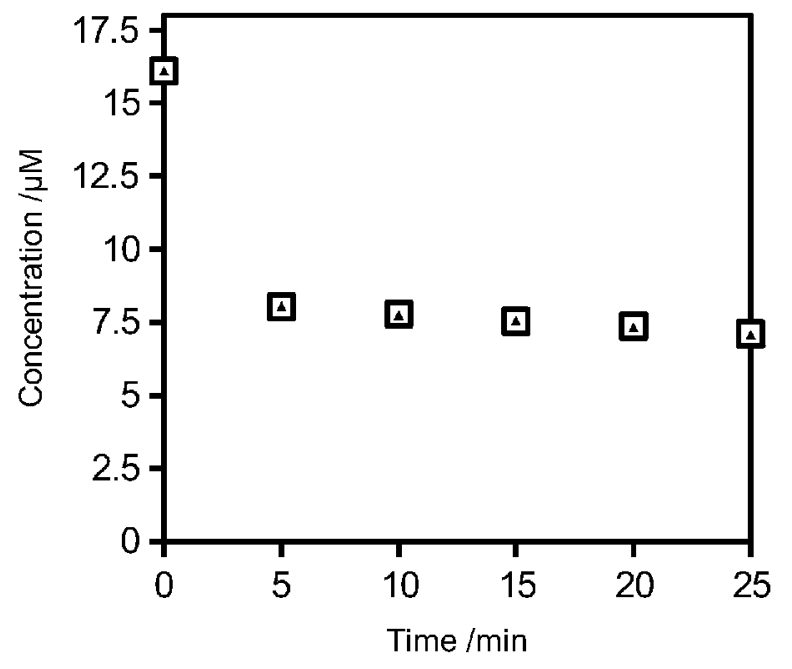

Figure S4. The photolysis of $16 \mu \mathrm{M}$ tylosin at $\mathrm{pH}$ values of 4.3 (open squares) and 9.1 (closed triangles) in the solar simulator, $250 \mathrm{~W} \mathrm{~m}^{-2}$. 


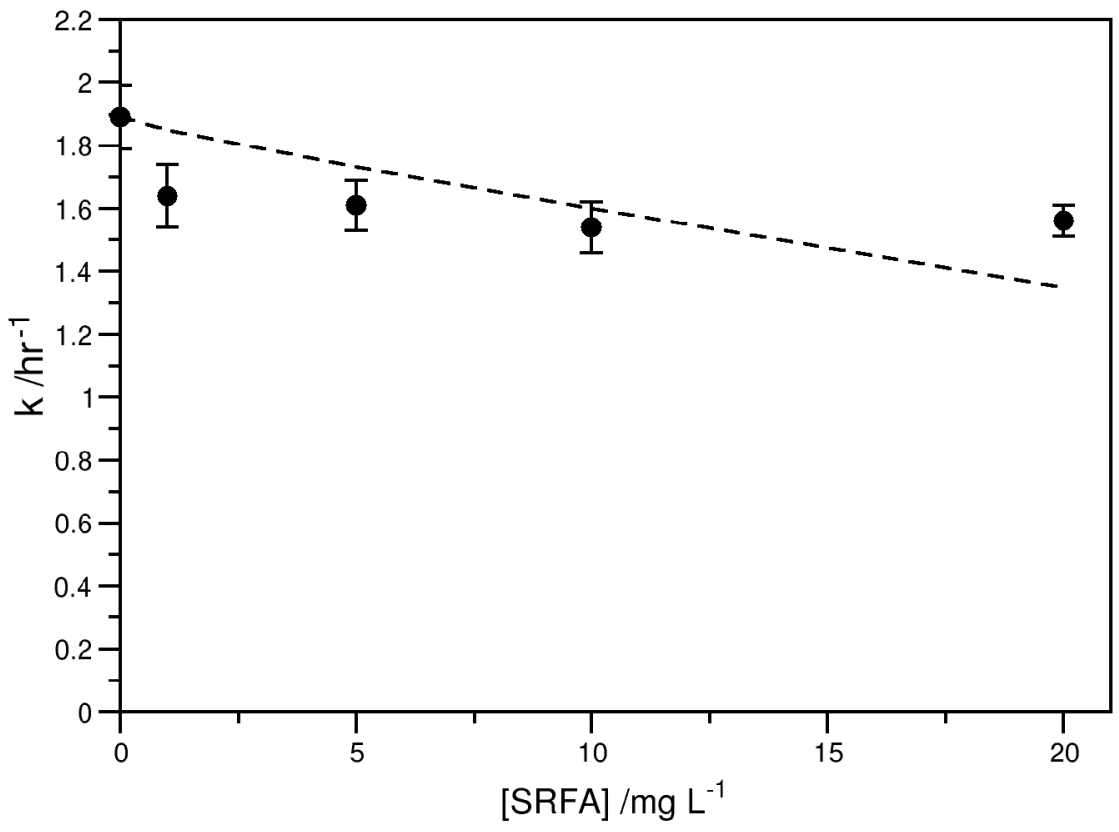

Figure S5. Pseudo-first-order rate constant for the photolysis of $100 \mu \mathrm{M}$ tylosin as a function of Suwanee River fulvic acid (SRFA) concentration: observed rate constants (circles) and theoretical (dashed line) direct photolysis rate constant calculated from the rate constant at $[\mathrm{SRFA}]=0$ and the light screening factor $\mathrm{S}$, based on both tylosin and SRFA absorbance measurements. Error bars represent the standard error of the linear regression of $\ln$ (concentration) vs time data used to calculate the rate constant. 

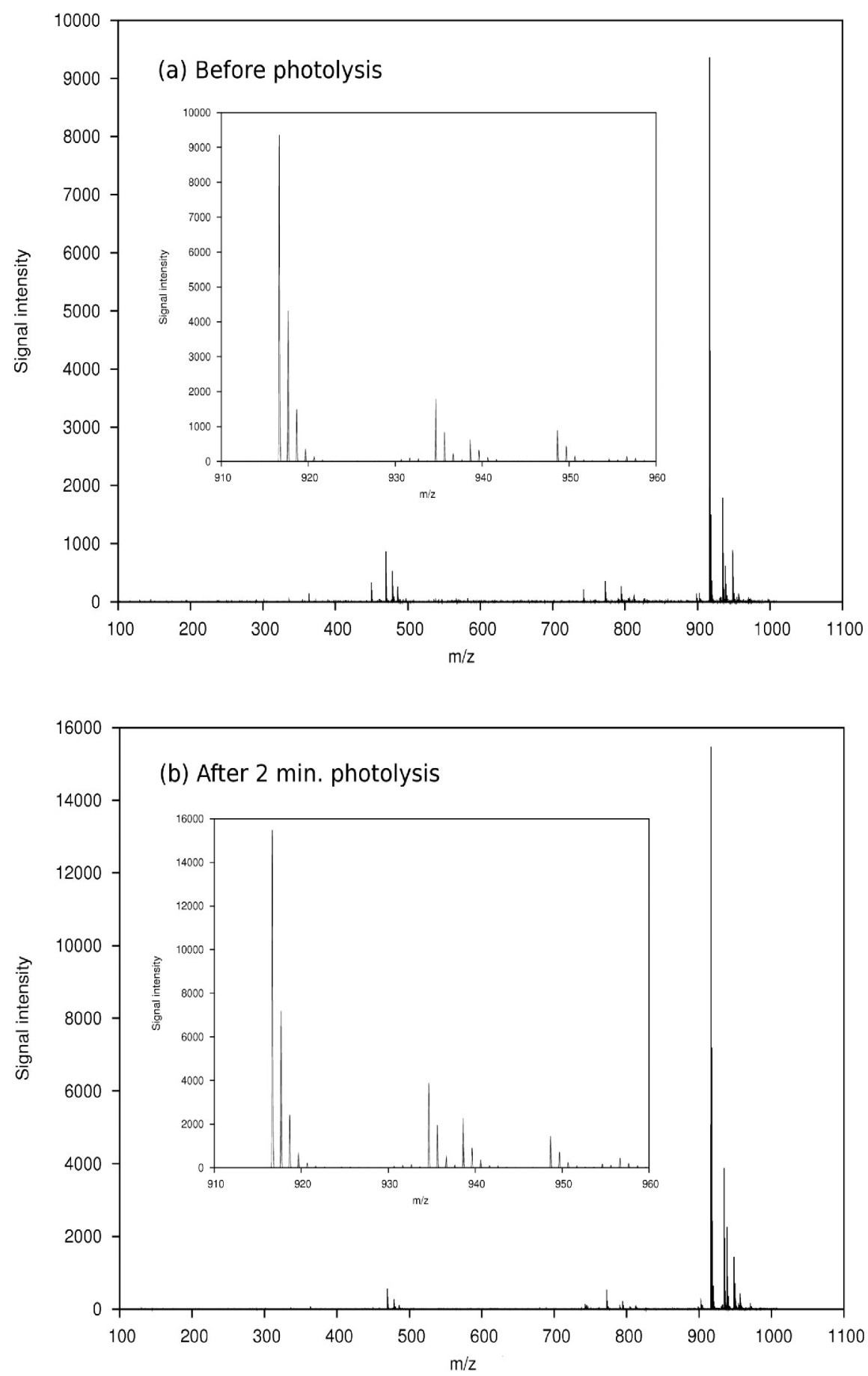

Figure S6. ESI-TOF mass spectra of a $100 \mu \mathrm{M}$ tylosin solution (a) before photolysis and (b) after 2 minutes of photolysis. The region containing the parent tylosin- $\mathrm{H}^{+}$ion $(\mathrm{m} / \mathrm{z}=916)$ is magnified in the inset. 

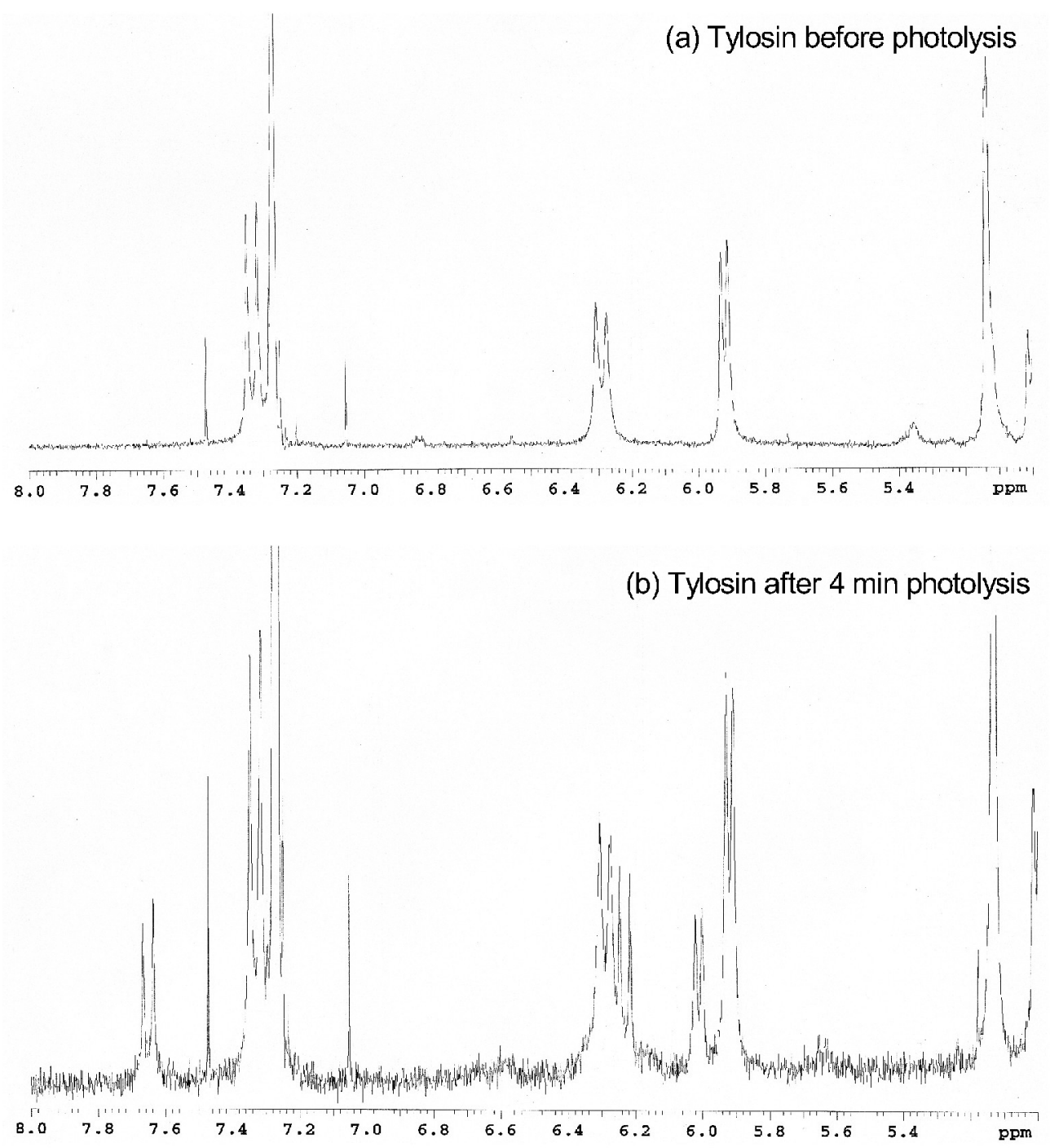

Figure S7. ${ }^{1} \mathrm{H}-\mathrm{NMR}$ spectra of tylosin in $\mathrm{CDCl}_{3}$ before (a) and after (b) 4 minutes of photolysis. 


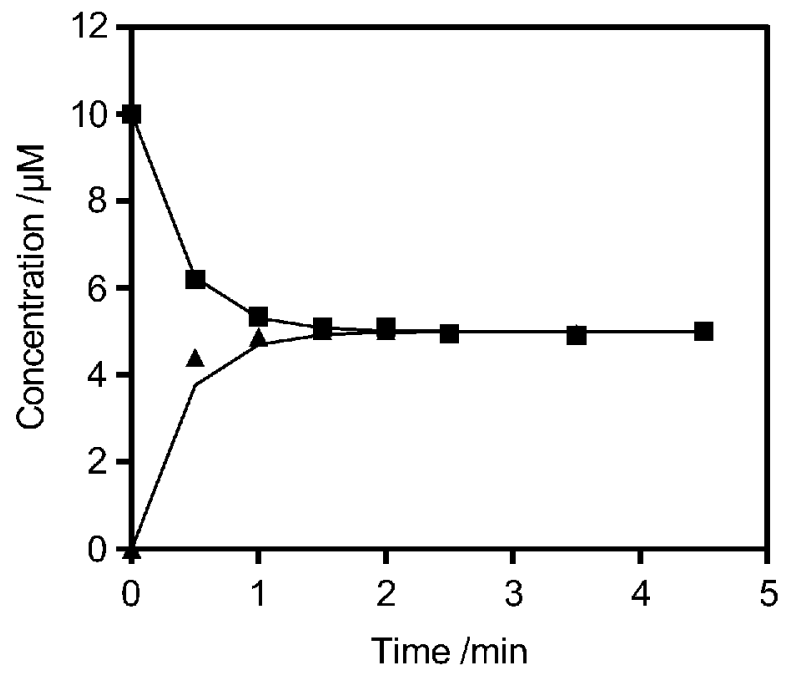

Figure S8. The photochemical equilibration of tylosin (squares) with theidentified isomer (triangles), fit to Equation 3 (lines). Isomer concentration calculated assuming 1:1 tylosinisomer ratio for the photoisomerization yield, as expressed in Equation 2 of the main text. 
Table S1. UV-vis absorbance measurements and calculated decadic molar absorptivity values for tylosin and the photoisomer.

\begin{tabular}{|c|c|c|c|c|}
\hline $\begin{array}{l}\text { Wavelength } \\
/ \mathrm{nm}\end{array}$ & $\begin{array}{l}\text { Tylosin } \\
39 \mu \mathrm{M} \\
/ \mathrm{AU}\end{array}$ & $\begin{array}{l}\text { Post- } \\
\text { Photolysis } \\
\text { /AU }\end{array}$ & $\begin{array}{l}\text { Tylosin } \\
\text { Absorptivity } \\
/ \mathrm{M}^{-1} \mathrm{~cm}^{-1}\end{array}$ & $\begin{array}{l}\text { Isomer } \\
\text { Absorptivity } \\
/ \mathrm{M}^{-1} \mathrm{~cm}^{-1}\end{array}$ \\
\hline 220 & 0.082 & 0.108 & 2103 & 3436 \\
\hline 221 & 0.079 & 0.104 & 2026 & 3308 \\
\hline 222 & 0.076 & 0.101 & 1949 & 3231 \\
\hline 223 & 0.073 & 0.098 & 1872 & 3154 \\
\hline 224 & 0.071 & 0.095 & 1821 & 3051 \\
\hline 225 & 0.069 & 0.093 & 1769 & 3000 \\
\hline 226 & 0.067 & 0.090 & 1718 & 2897 \\
\hline 227 & 0.065 & 0.088 & 1667 & 2846 \\
\hline 228 & 0.063 & 0.086 & 1615 & 2795 \\
\hline 229 & 0.062 & 0.084 & 1590 & 2718 \\
\hline 230 & 0.060 & 0.082 & 1538 & 2667 \\
\hline 231 & 0.059 & 0.080 & 1513 & 2590 \\
\hline 232 & 0.058 & 0.078 & 1487 & 2513 \\
\hline 233 & 0.057 & 0.076 & 1462 & 2436 \\
\hline 234 & 0.057 & 0.074 & 1462 & 2333 \\
\hline 235 & 0.056 & 0.073 & 1436 & 2308 \\
\hline 236 & 0.056 & 0.072 & 1436 & 2256 \\
\hline 237 & 0.056 & 0.071 & 1436 & 2205 \\
\hline 238 & 0.057 & 0.070 & 1462 & 2128 \\
\hline 239 & 0.058 & 0.069 & 1487 & 2051 \\
\hline 240 & 0.060 & 0.069 & 1538 & 2000 \\
\hline 241 & 0.062 & 0.070 & 1590 & 2000 \\
\hline 242 & 0.065 & 0.071 & 1667 & 1974 \\
\hline 243 & 0.069 & 0.072 & 1769 & 1923 \\
\hline 244 & 0.073 & 0.073 & 1872 & 1872 \\
\hline 245 & 0.077 & 0.075 & 1974 & 1872 \\
\hline 246 & 0.083 & 0.078 & 2128 & 1872 \\
\hline 247 & 0.089 & 0.081 & 2282 & 1872 \\
\hline 248 & 0.096 & 0.085 & 2462 & 1897 \\
\hline 249 & 0.103 & 0.089 & 2641 & 1923 \\
\hline 250 & 0.112 & 0.094 & 2872 & 1949 \\
\hline 251 & 0.121 & 0.100 & 3103 & 2026 \\
\hline 252 & 0.132 & 0.106 & 3385 & 2051 \\
\hline 253 & 0.143 & 0.113 & 3667 & 2128 \\
\hline 254 & 0.155 & 0.121 & 3974 & 2231 \\
\hline 255 & 0.169 & 0.130 & 4333 & 2333 \\
\hline 256 & 0.184 & 0.140 & 4718 & 2462 \\
\hline 257 & 0.200 & 0.150 & 5128 & 2564 \\
\hline 258 & 0.217 & 0.162 & 5564 & 2744 \\
\hline 259 & 0.235 & 0.174 & 6026 & 2897 \\
\hline 260 & 0.253 & 0.187 & 6487 & 3103 \\
\hline 261 & 0.272 & 0.200 & 6974 & 3282 \\
\hline 262 & 0.291 & 0.213 & 7462 & 3462 \\
\hline 263 & 0.310 & 0.228 & 7949 & 3744 \\
\hline 264 & 0.331 & 0.242 & 8487 & 3923 \\
\hline 265 & 0.353 & 0.258 & 9051 & 4179 \\
\hline 266 & 0.377 & 0.275 & 9667 & 4436 \\
\hline 267 & 0.401 & 0.291 & 10282 & 4641 \\
\hline 268 & 0.424 & 0.308 & 10872 & 4923 \\
\hline 269 & 0.448 & 0.325 & 11487 & 5179 \\
\hline 270 & 0.474 & 0.343 & 12154 & 5436 \\
\hline
\end{tabular}




\begin{tabular}{|c|c|c|c|c|}
\hline 271 & 0.501 & 0.362 & 12846 & 5718 \\
\hline 272 & 0.527 & $\odot .381$ & 13513 & 6026 \\
\hline 273 & 0.552 & 0.400 & 14154 & 6359 \\
\hline 274 & 0.577 & 0.419 & 14795 & 6692 \\
\hline 275 & 0.603 & 0.439 & 15462 & 7051 \\
\hline 276 & 0.627 & 0.458 & 16077 & 7410 \\
\hline 277 & 0.651 & 0.476 & 16692 & 7718 \\
\hline 278 & 0.674 & 0.495 & 17282 & 8103 \\
\hline 279 & 0.697 & 0.513 & 17872 & 8436 \\
\hline 280 & 0.720 & 0.531 & 18462 & 8769 \\
\hline 281 & 0.741 & $\odot .549$ & 19000 & 9154 \\
\hline 282 & 0.761 & 0.565 & 19513 & 9462 \\
\hline 283 & 0.779 & 0.580 & 19974 & 9769 \\
\hline 284 & 0.794 & 0.595 & 20359 & 10154 \\
\hline 285 & 0.808 & 0.608 & 20718 & 10462 \\
\hline 286 & 0.819 & 0.619 & 21000 & 10744 \\
\hline 287 & 0.828 & 0.629 & 21231 & 11026 \\
\hline 288 & 0.835 & 0.638 & 21410 & 11308 \\
\hline 289 & 0.838 & 0.645 & 21487 & 11590 \\
\hline 290 & 0.840 & 0.650 & 21538 & 11795 \\
\hline 291 & 0.840 & 0.654 & 21538 & 12000 \\
\hline 292 & 0.837 & 0.657 & 21462 & 12231 \\
\hline 293 & 0.831 & 0.657 & 21308 & 12385 \\
\hline 294 & 0.823 & 0.656 & 21103 & 12538 \\
\hline 295 & 0.813 & 0.654 & 20846 & 12692 \\
\hline 296 & 0.800 & $\odot .649$ & 20513 & 12769 \\
\hline 297 & 0.785 & 0.644 & 20128 & 12897 \\
\hline 298 & 0.768 & 0.636 & 19692 & 12923 \\
\hline 299 & 0.749 & 0.627 & 19205 & 12949 \\
\hline 300 & 0.728 & 0.617 & 18667 & 12974 \\
\hline 301 & 0.706 & 0.605 & 18103 & 12923 \\
\hline 302 & 0.682 & 0.592 & 17487 & 12872 \\
\hline 303 & 0.657 & 0.577 & 16846 & 12744 \\
\hline 304 & 0.630 & 0.562 & 16154 & 12667 \\
\hline 305 & 0.603 & $\odot .545$ & 15462 & 12487 \\
\hline 306 & 0.574 & 0.527 & 14718 & 12308 \\
\hline 307 & 0.545 & 0.508 & 13974 & 12077 \\
\hline 308 & $\bullet .515$ & 0.488 & 13205 & 11821 \\
\hline 309 & 0.485 & 0.467 & 12436 & 11513 \\
\hline 310 & 0.455 & 0.446 & 11667 & 11205 \\
\hline 311 & 0.426 & 0.426 & 10923 & 10923 \\
\hline 312 & ๑. 397 & 0.404 & 10179 & 10538 \\
\hline 313 & 0.367 & 0.383 & 9410 & 10231 \\
\hline 314 & 0.339 & 0.361 & 8692 & 9821 \\
\hline 315 & 0.311 & 0.339 & 7974 & 9410 \\
\hline 316 & 0.284 & 0.318 & 7282 & 9026 \\
\hline 317 & 0.259 & 0.297 & 6641 & 8590 \\
\hline 318 & 0.235 & 0.276 & 6026 & 8128 \\
\hline 319 & 0.212 & 0.256 & 5436 & 7692 \\
\hline 320 & 0.190 & 0.236 & 4872 & 7231 \\
\hline 321 & 0.170 & 0.217 & 4359 & 6769 \\
\hline 322 & 0.152 & 0.199 & 3897 & 6308 \\
\hline 323 & 0.136 & 0.182 & 3487 & 5846 \\
\hline 324 & 0.120 & 0.165 & 3077 & 5385 \\
\hline 325 & 0.107 & 0.150 & 2744 & 4949 \\
\hline 326 & 0.095 & 0.136 & 2436 & 4538 \\
\hline 327 & 0.083 & 0.123 & 2128 & 4179 \\
\hline 328 & 0.073 & 0.110 & 1872 & 3769 \\
\hline
\end{tabular}




\begin{tabular}{|c|c|c|c|c|}
\hline 329 & 0.064 & 0.098 & 1641 & 3385 \\
\hline 330 & 0.057 & 0.087 & 1462 & 3000 \\
\hline 331 & 0.050 & 0.078 & 1282 & 2718 \\
\hline 332 & 0.044 & 0.069 & 1128 & 2410 \\
\hline 333 & 0.039 & 0.061 & 1000 & 2128 \\
\hline 334 & 0.034 & 0.053 & 872 & 1846 \\
\hline 335 & 0.030 & 0.047 & 769 & 1641 \\
\hline 336 & 0.027 & 0.041 & 692 & 1410 \\
\hline 337 & 0.024 & 0.036 & 615 & 1231 \\
\hline 338 & 0.021 & 0.031 & 538 & 1051 \\
\hline 339 & 0.019 & 0.028 & 487 & 949 \\
\hline 340 & 0.017 & 0.024 & 436 & 795 \\
\hline 341 & 0.016 & 0.022 & 410 & 718 \\
\hline 342 & 0.014 & 0.019 & 359 & 615 \\
\hline 343 & 0.013 & 0.017 & 333 & 538 \\
\hline 344 & 0.012 & 0.015 & 308 & 462 \\
\hline 345 & 0.011 & 0.014 & 282 & 436 \\
\hline 346 & 0.010 & 0.012 & 256 & 359 \\
\hline 347 & 0.009 & 0.011 & 231 & 333 \\
\hline 348 & 0.008 & 0.010 & 205 & 308 \\
\hline 349 & 0.008 & 0.009 & 205 & 256 \\
\hline 350 & 0.007 & 0.008 & 179 & 231 \\
\hline 351 & 0.007 & 0.007 & 179 & 179 \\
\hline 352 & 0.006 & 0.007 & 154 & 205 \\
\hline 353 & 0.006 & 0.006 & 154 & 154 \\
\hline 354 & 0.005 & 0.006 & 128 & 179 \\
\hline 355 & 0.005 & 0.005 & 128 & 128 \\
\hline 356 & 0.005 & 0.005 & 128 & 128 \\
\hline 357 & 0.004 & 0.004 & 103 & 103 \\
\hline 358 & 0.004 & 0.004 & 103 & 103 \\
\hline 359 & 0.004 & 0.004 & 103 & 103 \\
\hline 360 & 0.004 & 0.003 & 103 & 51 \\
\hline 361 & 0.003 & 0.003 & 77 & 77 \\
\hline 362 & 0.003 & 0.003 & 77 & 77 \\
\hline 363 & 0.003 & 0.003 & 77 & 77 \\
\hline 364 & 0.003 & 0.002 & 77 & 26 \\
\hline 365 & 0.003 & 0.002 & 77 & 26 \\
\hline 366 & 0.002 & 0.002 & 51 & 51 \\
\hline 367 & 0.002 & 0.002 & 51 & 51 \\
\hline 368 & 0.002 & 0.002 & 51 & 51 \\
\hline 369 & 0.002 & 0.001 & 51 & 0 \\
\hline 370 & 0.002 & 0.001 & 51 & $\theta$ \\
\hline
\end{tabular}




\section{References}

Boreen, A. L.; Arnold, W. A.; McNeill, K., 2004. Photochemical fate of sulfa drugs in the aquatic environment: Sulfa drugs containing five-membered heterocyclic groups. Environ. Sci. Technol. 38, 3933-3940.

Dulin, D. and Mill, T. 1982 Development and evaluation of sunlight actinometers. Environ. Sci. Technol. 16, 815-820.

Gueymard, C. A. 1995. SMARTS, A simple model of the atmospheric radiative transfer of sunshine: algorithms and performance assessment. Cocoa, FL, Florida Solar Energy Center. Technical Report No. FSEC-PF-270-95.

Gueymard, C. A. 2001. Parameterized transmittance model for direct beam and circumsolar spectral irradiance. Sol. Energy 75, 325-346.

Kasha, M. 1950. Characterization of electronic transitions in complex molecules. Discuss. Faraday Soc. 9, 14-19.

Leifer, A. The Kinetics of Environmental Aquatic Photochemistry: Theory and Practice. American Chemical Society: Washington DC, 1988.

Schwarzenbach, R. P.; Gschwend, P. M.; Imboden, D. M. Environmental Organic Chemistry, $2^{\text {nd }}$ Ed.; John Wiley \& Sons, Inc.: Hoboken, NJ, 2003.

Werner, J. J.; Arnold, W. A.; McNeill, K. 2006. Water hardness as a photochemical parameter: Tetracycline photolysis as a function of calcium concentration, magnesium concentration and $\mathrm{pH}$. Environ. Sci. Technol. 40:7236-7241.

Zepp, R. G.; Cline, D. M. 1977. Rates of direct photolysis in aquatic environment. Environ. Sci. Technol. 11, 359-366.

Zepp, R. G. 1978. Quantum yields for reaction of pollutants in dilute aqueous solution. Environ. Sci. Technol. 12, 327-329. 